\title{
Placental Hypertrophy
}

National Cancer Institute

\section{Source}

National Cancer Institute. Placental Hypertrophy. NCI Thesaurus. Code C118162.

Aberrant growth of the placenta. 